\title{
Managing the retention or divestment of material possessions in the transition to retirement: implications for sustainable consumption and for later-life wellbeing
}

\author{
Susan Venn* (D) and Kate Burningham \\ Department of Sociology, University of Surrey, Guildford, UK \\ ${ }^{\star}$ Corresponding author. Email: s.venn@surrey.ac.uk
}

(Accepted 15 December 2020; first published online 10 March 2021)

\begin{abstract}
It has been argued that lifecourse transitions are transformative moments for individuals when lifestyles, habits and behaviours are potentially open to contemplation and change. Within sustainability research such 'moments of change' are regarded as offering potential to encourage less environmentally damaging consumption patterns. Research on consumption indicates that orientations to material goods and their affective significance are complex. Whilst sociological work understands attachment to things as integral to maintaining kinship relations, this is hard to reconcile with long-standing moral concerns about materialism and psychological research which indicates a negative relationship between the acquisition of material objects and wellbeing, and the environmental implications of acquiring and divesting 'stuff. Yet there has been little engagement with how older people orient to their material possessions and divestment, the implications of this for later-life wellbeing and for environmental sustainability. In this paper, we draw these different strands of work together to understand how retirees relate to their material possessions and their divestment. Drawing on serial interviews with individuals in the United Kingdom, we explore how the transition to retirement highlights the complexity of participants' attachment to things. While some items had profound relational significance, others were experienced as troublesome. Decisions on what to divest were shaped by pragmatic considerations and levels of attachment, whilst modes of divestment were aligned with values of thrift.
\end{abstract}

Keywords: lifecourse transitions; retirement; sustainability; consumption; divestment; wellbeing; material flows

\section{Introduction}

The transition to retirement is a well-researched topic within gerontology where it has been explored as a potential point at which to encourage later-life wellbeing through advice on maintaining an active and healthy lifestyle (Heaven et al., 2015), 
on pension planning provisions and financial security (Ginn, 2003), as well as on facilitating the shift in identity following loss of work status (Barnes and Parry, 2004). Retirement has also been examined as a portal into another transition of later, and much older age, or as suggested by Gilleard and Higgs (2013: 368), a fourth age of a 'feared state of becoming' which is perceived as being defined by frailty and often increasing poverty. Retirement has therefore been established within gerontology as a point at which people pause to consider their present circumstances, their future trajectories and are likely to 'confront their own mortality' (Price et al., 2000: 179).

Lifecourse transitions are also a topic of interest within the literature on sustainable consumption, being tentatively regarded as promising 'moments of change' when individuals consider the lives they currently lead, and whether changes are necessary, or desirable, for the future (Thompson et al., 2011; Venn et al., 2017; Burningham and Venn, 2020). As individuals change from one role or situation to another, it is argued they engage in self-reflexivity and as a result are more likely to be open to suggestions for shifting existing behaviours and habits in a more sustainable direction (Giddens, 1991; Thompson et al., 2011; Goodwin and O'Connor, 2014). Yet within this work, the transition to retirement as a potential window of opportunity to encourage more sustainable patterns of consumption has only received scant attention, and indeed, older people in general are often absent from environmental sustainability discussions (for exceptions, on later-life travel practices see Fox et al., 2017; Hitchings et al., 2018; and on consumption, see Venn et al., 2017; Burningham and Venn, 2020). This is problematic given current projections that the proportion of older people in the United Kingdom (UK) is set to rise dramatically over the next 25 years (Coates et al., 2019).

More recently the idea that lifecourse transitions constitute a single 'moment of change' has been critiqued and it has been shown that they can be unexpected, incomplete and multiple (Grenier, 2012; Shirani et al., 2017; Burningham and Venn, 2020). Retirement, in particular, is known to be an ongoing journey, and more frequently encompasses 'complex flows between nonretirement, partial retirement and complete retirement' (Thompson et al., 2011: 84). Retirement is likely to continue to be fluid and changeable as a result of the abolition of a fixed retirement age in the UK and the state pension age rising over the coming years (Thompson et al., 2011).

Retirement also differs from other transitions in that expectations for more leisure time, and a loosening of the formal daytime structure defined by employment, are known to create opportunities for engaging in more and different forms of consumption (Atchley, 1975; van Solinge and Henkens, 2008). More specifically, the current generation of retirees (referred to as 'baby-boomers' and born between 1946 and 1964), are regarded as distinct from other generations in that the cultural field by which they are defined ostensibly encompasses personal agency, individualised lifestyles and excessive consumption practices which seek to deny old age and which are said to represent the 'good life' (Schulze, 1997; Gilleard and Higgs, 2009). However, Leach et al. (2007), in their study of baby-boomers' consumption patterns, noted that their orientations to consumption were more complex - whilst being critical of younger generations' consumerist lifestyles, and respecting the frugal values of the previous generation, they had their own expectations for 
retirement which included travel, leisure pursuits, and home purchases and improvements.

In this paper, we bring together these different disciplinary perspectives as we follow participants on their journey through the transition to retirement. As we do, we explore within their narratives how the prospect and experience of retirement served to heighten their orientation to the objects they have acquired and which have accompanied them along the lifecourse, and how they distinguish between things of value and problematic 'stuff. In alignment with work that highlights how disposal is also a part of the journey of consumption, we include participants' considerations of modes of divestment (Hetherington, 2004; Gregson et al., 2007: 187). We commence with a review of the literature on the acquisition, collection and disposal of material possessions across the lifecourse, before considering two distinctive perspectives on the relationship between material possessions and wellbeing whereby, on the one hand, objects are demonstrated to provide comfort, meaning and enhance wellbeing (Kroger and Adair, 2008; Miller, 2008; Smith and Ekerdt, 2011) and, on the other, how acquiring, owning and the maintenance of 'stuff is characterised as potentially problematic in terms of wellbeing (Bauer et al., 2012; Isham et al., 2019).

\section{Acquisition, ownership, divestment - following the 'material flow'}

Objects are accumulated along the lifecourse in various ways; some are acquired as a result of engaging with the numerous consumerist messages encouraging the endless 'acquisition and use of material goods' as part of an ongoing cycle of replacing old with new (Brown and Vergragt, 2015: 309; see also Smith and Ekerdt, 2011). Others are gifted and collected as part of making and maintaining relationships, as a way of presenting and securing a sense of self through their symbolic meaning, or as a means of recalling memories (Csikszentmihalyi and Rochberg-Halton, 1981; Kroger and Adair, 2008). However they are obtained, they are carried along through the lifecourse as a 'convoy' of objects which fluctuate in size according to circumstances, whilst also requiring some form of maintenance or management (Ekerdt et al., 2004).

Arguments have also been made for the inclusion of modes of divestment as a part of the 'material flows' that take place within and outside the home as a further route to understanding everyday household consumption and waste habits (Hetherington, 2004: 157; Gregson et al., 2007: 187). Trentmann (2018: 624), for example, has highlighted the need to include alternative forms of disposal when examining household waste practices, arguing against considering the act of throwing away in isolation from other means of disposal and for including 'gifting, giving things to charity shops, or storing them in the garage', even though this means unwanted items remain in circulation and continue to be part of the cycle of consumption. It therefore seems important, when considering retirement as a moment of reflection on material possessions, to also include retirees' approaches to disposal.

Hitherto, when exploring how older people manage their accumulated possessions, the emphasis has mostly been on the transition in much later life from home to a residential setting, when family members are largely responsible for negotiating the management of the disposal or otherwise of items (Price et al., 
2000; Stevens et al., 2019). Little research has been conducted on retirement as a transition point where individuals may reflect on the belongings currently in their homes, what to do with them and how. This omission is surprising given that retirement is known to be a moment of heightened awareness of all aspects of current and future life (Thompson et al., 2011; Shirani et al., 2017).

The current generation approaching or entering retirement also face contradictory discourses and movements relating to ways of consuming and divesting (Evans, 2015; Ouellette, 2019). For example, retirees are strategically being targeted as a potentially lucrative market in areas such as leisure, travel and household goods and services, with the 'increasingly older consumer market' being encouraged to increase their rates of consumption, as part of their personal responsibility for contributing towards the UK's economic growth (International Longevity Centre UK, 2019: 11). Yet equally, there are numerous options for purchasing advice and support on how to divest and declutter in retirement (see e.g. https://www.evergreenlifestyle.co.za/; bystored.com). Marie Kondo's encouragement to the better off to embrace minimalism by confronting clutter in the home and removing things that do not 'spark joy', suggests individuals' lives will then be magically transformed for the better, albeit with no consideration of where the 'joyless' items go (Kondo, 2011; Van Oyen, 2020). Margaret Magnusson's (2017) book on The Gentle Art of Swedish Death Cleaning, or döstädning, has taken this movement further to specifically target older people and their families, encouraging them to sort through and rationalise their belongings, presumably before it is too late to do so.

These contradictory discourses are problematic in that there is an overemphasis on individual responsibility for change, with issues of household class, income and gender being ignored (Ouellette, 2019). They are also problematic in relation to sustainable consumption practices given that they privilege the throwing away of items rather than their repair or reuse, and ignore both the damaging environmental impact and cheap labour involved in producing them in the first place (Ouellette, 2019). We turn now to consider in more detail the ambiguity and complexity of relationships with material objects and their role in supporting or compromising wellbeing.

\section{Material attachment and affinity}

Work that focuses on the benefits of acquiring and owning items emphasises how their significance extends beyond their functional value, to representing the importance of our relationships with and to others, and with ourselves (Jackson, 2005b). The items we are gifted and those we gift demonstrate our care and love for others, and signify the essence of our relationships in a tangible way by bringing those relationships into the present moment through their presence (Csikszentmihalyi and Rochberg-Halton, 1981; Bourdieu, 1984; Jackson, 2005a; Miller, 2008, 2012).

Objects which are passed on to others, either through gifts or inheritance, therefore act as 'receptacles for memories, reminders of family, past, present and future' and are intrinsically valuable for wellbeing (Holmes, 2019: 175; see also Csikszentmihalyi and Rochberg-Halton, 1981). Yet these items need not necessarily be 'keepsakes or heirlooms' which are merely decorative, or those which appear to have extrinsic value (Holmes, 2019: 175). Practical, everyday objects that are passed 
on can also serve as reminders of the person who used them, and even of the experience shared during their use, such as items of kitchen equipment prompting reminders of a shared meal or of times spent baking together (Habermas and Praha, 2002; Holmes, 2019).

Within the social sciences, the link between identity formation and ownership of material possessions is well established (Dittmar, 1991; Shankar et al., 2009). Giddens and others, for example, have highlighted how, in contemporary culture, identities are not static, but rather are dynamic and changeable across the lifecourse so that individuals partly rely on acts of consumption to create and communicate their identities and status (Belk, 1988; Giddens, 1991; Shankar et al., 2009; Ladik et al., 2015). Thus, as identities shift across the lifecourse, those items that represent former identities or status may be disposed of, or put out of sight and into storage, and new ones purchased to reflect new identities (Shankar et al., 2009; Ladik et al., 2015).

In much later life, objects can have greater relevance in identity maintenance as they connect individuals to the past and may be used as a means of coping with experiences of loss of family members, work roles and help with the transition into residential care (Belk, 1988; Kroger and Adair, 2008; van Hoof et al., 2016). Therefore, the constancy of an object's existence helps to act as a buffer against change and discontinuity over time, and to offer a sense of security in later life, even if the object itself is mundane (Kroger and Adair, 2008; Miller, 2010). Decisions on what to keep and what to dispose of may therefore be particularly challenging in later life (Kroger and Adair, 2008; Ekerdt and Baker, 2014).

\section{Clutter, stuff and 'matter out of place'}

There is, however, also ample evidence of the negative relationship between materialism, consumption and subjective wellbeing, which suggests there is a 'wellbeing paradox' whereby rising levels of income and consumption do not lead to a rise in individual and societal wellbeing and may even be harmful (Easterlin, 1974; Belk, 1988; Jackson, 2005a, 2005b, 2016; Dittmar et al., 2014).

Having the means to purchase whatever is desired does not necessarily improve wellbeing, rather it is known to lead to a heightened awareness of the discrepancy between what is owned, and what is yet to be owned, as in the latest model, newest version or current trend (Norris and Larsen, 2010). Households in Western Europe contain more stuff than can easily be used, with duplicate or even triplicate items, like televisions, in households, so that 'superfluity' and 'abundance' have become the new norm (Schor, 1997).

Material goods are part of the spaces people inhabit, and are part of the way domestic spaces are configured (Hand et al., 2005; Horne et al., 2011). An excess accumulation of 'stuff therefore has the ability to impinge on idealised norms of what constitutes home in the eyes of those who live there, and of how visitors may perceive and judge how the home is configured (Gregson, 2007). Mary Douglas's (1984: 35) work highlighted how the social world is ordered by categories, and that anything which contravenes that order is 'dirt' - not in the sense of disease or being unhealthy, but rather as that which transgresses order, and therefore needs to be put 'out of place'. Therefore, unwanted items which threaten the social order, security and norms around comfort of the home are the equivalent 
of dirt, or 'matter out of place' (Douglas, 1984: 35; Hetherington, 2004; Gregson et al., 2007). The accumulation of things or objects in the home is therefore potentially a moral question, in that too much 'stuff not only highlights the consequences of excessive consumption, but also allows for moral judgements on those who live in messy spaces (Löfgren, 2017).

The stuff collected on life's journey, whether or not it 'sparks joy', is functional, or remains stashed in invisible places such as the loft, or shed, can be burdensome, requiring a labour of ownership (cleaning, arranging, storing) and ultimately its disposal (Kondo, 2011; Ekerdt and Baker, 2014). Accumulated quantities of stuff may be regarded as burdensome as individuals become aware of the need to tackle its disposal before a 'more restricted lifeworld' renders them unable to manage their removal or poses a potential barrier to a later-life transition into residential care (Ekerdt et al., 2004: S266; Kroger and Adair, 2008). Stuff can also be problematic for wellbeing if the quantity accumulated highlights the moral consequences of engaging in lifelong consumption (Ekerdt and Baker, 2014).

Following a description of our methods, we draw on participants' narratives to illustrate how the transition to retirement prompted an evaluation of possessions within the home, and a consideration of what could be regarded as valuable and retained, or what constituted 'clutter'. We then move on to consider preferred modes of divestment before concluding with some critical reflections on material orientations through the transition to retirement.

\section{Study design}

The data analysed in this paper are from a project which sought to explore individuals' experiences of the transition to first-time parenthood or to retirement, and the potential for lifecourse transitions to encourage more sustainable ways of living. Ten participants planning to retire in the near future were recruited from each of four locations: South London, Kent, Lancashire and Scotland, but for the purposes of this paper we are drawing on interviews with participants from South London and Scotland $(\mathrm{N}=20)$.

Each participant was invited to undertake three in-depth interviews in their own homes $(\mathrm{N}=60$ interviews), after which they completed a seven-day journal of what they did and how they felt. The first interview was planned to take place prior to retirement, and the two subsequent interviews at further eight-month intervals. The first two completed journals were used at the start of the second and third interviews as prompts for discussing what had changed since the previous visit. Participants ranged in age from 45 to 69, with an average age of 63, and were equally divided by gender. All were white British, and were recruited from a range of socio-economic status using the National Readership Survey social grading system based on the participant's occupation, although difficulties in recruitment led to a majority of the participants presented here being from socio-economic groups $\mathrm{A}, \mathrm{B}$ and $\mathrm{C}$, that is from those with managerial or supervisory occupational roles rather than from the skilled/unskilled or unemployed. Reflecting the current complex and fluid nature of household living arrangements, the majority of the participants were partnered and/or living in households with children or other family members. Only three participants were living alone (all female). Furthermore, 
and as noted in the literature, the transition to retirement was not always a straightforward longitudinal process, with some participants retiring earlier than planned, others moving in and out of retirement, and some not having retired at all by the final interview (Grenier, 2012; Goodwin and O'Connor, 2014; Burningham and Venn, 2020).

Interviews were exploratory in nature, broadly developed around understanding what was important to participants in their everyday lives, and were to reflect on aspects of change about which they felt positive or negative as they make the transition to retirement. Whilst an interview topic guide was used as a framework to ensure consistency across all interviews, participants were encouraged to talk freely and openly (Patton, 2002). Questions during the interview focused on everyday practices deployed around themes such as what is important about their home, food purchase and consumption, modes of transport and leisure activities, and families and social networks. Participants were not recruited on the basis of their environmental beliefs, nor were questions concerning what might constitute a sustainable lifestyle asked until the final interview. This approach allowed us to focus on gaining an understanding of the participants' everyday activities, without any undue emphasis being placed on the sustainability or otherwise of these activities. All interviews were fully transcribed and the software package versions NVivo 10 and 11 were used to support a thematic analysis approach (Evans, 2018). Emerging themes relating to plans for material possessions and the home were identified within participants' narratives of expectations for retirement, and coded by reviewing responses across the dataset cross-sectionally, and longitudinally, thus enabling us to observe commonalities and differences between participants and over time (Saldaña, 2003). Discussions on the validity of identified themes were undertaken with other members of the research team.

To protect the anonymity and confidentiality of the participants, pseudonyms have been used and the location and interview from which the quotation is taken is indicated following the quotation (e.g. Christopher, Scotland, 2). All participants received a small honorarium in compensation for their time; confidentiality and anonymity were assured and ethical approval was granted by the University of Surrey.

We commence this paper by showing how the transition to retirement prompted an appraisal of a post-work future and a contemplation of how to remain productive. We move on to suggest that retirement opened up space for participants to consider the items that had been collected along the lifecourse and to evaluate them for their symbolic meanings and attachment, as well as for possible disposal. We then reflect on how modes of divestment for those items designated waste were shaped by pragmatic considerations, and alignment with values of thrift. In our discussion we highlight two ambiguities: firstly, the complexity of peoples' relationships to their possessions and, secondly, how the messiness of lifecourse transitions can disrupt current and future plans. Finally, we consider the role of lifelong consumption and later-life divestment in terms of work in the area of sustainable consumption.

\section{Contemplating retirement}

The first of the three interviews with participants was conducted approximately eight months prior to the expected date of retirement. The prospect of retirement 
evoked two narratives involving time: firstly, it was anticipated there would be more time after stopping work, with participants either looking forward to having more time available and how they would fill it, or fearful of too much time, which would lead to them missing the structure and productiveness of a working day:

Interviewer: Are you looking forward to retirement?

William: I'm looking forward to doing all the things that you know, find the time to do things now. That's the most important thing, finding the time. (London, 1)

Interviewer: And can you tell me a little bit more about how you feel about, making that change between full-time work and retirement?

David: If you don't fill your days what are you going to do? I've decided that I really need to have a structured day because I know that if I stay in bed until 10 am or 11 am then I'd go to bed later. I'm not going to be one of those who retires and then does nothing and dies. (Scotland, 1)

I do know myself, I've got that terribly ... protestant ethic about, really you've got to be working you know, it's not worthwhile if you haven't achieved something. (Veronica, London, 1)

Secondly, and paradoxically, narratives were also of the spectre of limited time with the approach of retirement signalling a further impending transition, to older age, frailty and even death:

Interviewer: That's what you think you have less of at the moment [time]? William: You get to a certain age and you think I haven't got that many years left (laughter) ... I know a few people that have died at sort of like an early age but as you sort of get to thinking, I don't know, and because the years go past so quickly, so you feel like you know hang on I might only have 15, 20 years left and that, you know, I want to be sort of reasonably fit ... I think that's what it is, you simply run out of time. (London, 1)

There is known to be variability in the extent to which individuals plan for their retirement, and this was replicated within our own sample with some having clear plans and projects they would be undertaking, whilst others were less clear about what they would do with their free time (Moffatt and Heaven, 2017). Ekerdt (1986) suggests that the adoption of a 'busy ethic' in retirement is necessary in order to authenticate non-work-focused activities, to defend individuals against judgements of 'obsolescence' and to legitimise a new retirement identity. Veronica's guilt about being unproductive and David's fear of doing nothing drew on normative expectations that in order to be successful at retirement, retirees should remain busy at home in order to replace being busy at work (Ekerdt, 1986; Lee and Law, 2004). Unsurprisingly then, many participants envisaged ways of keeping busy in the immediate post-retirement phase which included refashioning of the home 
by repairing, decorating and replacing old or out-of-date items ('the main plan [in retirement] is actually finishing off the house'; William, London, 1) and reconfiguring the home to address their lifelong collection of items ('I won't need clothes for work - so there's going to be a good clean out of the wardrobe'; Adele, Scotland, 1). The challenge in managing their homes and possessions, however, was in the ambiguity and complexity of orientations and levels of attachment to the accumulated items, with participants having a 'material affinity' with some (Holmes, 2019), while perceiving others as 'matter out of place' (Douglas, 1984).

\section{Things matter}

When discussing what may change in retirement and beyond, participants often spoke of alterations they may make to their home, or the prospect of retirement leading to moving home at some point in the future. These narratives also included commentaries of attachment to home, and to items in their possession - some of which had extrinsic value, whilst others were seemingly ordinary, everyday objects which gave pleasure when they were used. During Gail's first interview, for example, she explained how she had started the process of assessing her belongings because of a possible move when she retires, 'I have slimmed down a lot but there are some things which mean a lot to me and I like very much, and I will always like'. This included a set of favourite saucepans which formed part of her own 'material convoy', 'you collect them over time', and which she was comfortable with to the extent they were not only useful but also redolent of a close family relationship (Holmes, 2019), 'Certain pans, I like living with them, I like having them around me.' She anticipated passing them on to her daughter in the future so that she may have the same material and relational connection with them, 'I like to think my daughter will have them when she grows up' (Gail, London, 1).

Items in the home were also significant because of whom they were gifted by initially, and because of the way they provided a connection to family histories and stories, and evoked memories of the giver of the item, or of other family members who may have come into contact with them. Margaret spoke of things of importance to her in the context of a possible future move once she and her husband were retired ('We probably kind of imagine there will be become a time where it might be difficult for us, it might be expensive I suppose to keep it [their home]') which would require her considering what things were most important to her:

The kind of things that might be important are the little things that have been given me, more than the actual big items. They are not important. We tend to keep things for as long as possible and change things as little as possible. There would be little things that maybe somebody gave you that you really like or that belonged to your mother or your father. (Margaret, Scotland, 1)

Margaret's use of the word 'things' for objects of importance, to differentiate from 'items' which are not, resonates with Ingold's (2010) distinction between objects and things, whereby objects are perceived as matter that are inert, unused or out of sight, and things as being in use, tangled up with other things, and connected to family and friends. Thus, in using the term 'thing' when describing the items 
in her home, Margaret is imagining them with a past, present and future, in a 'gathering of the threads of life' (Ingold, 2010: 4).

The strength of the threads connecting things to family members intensified as the relationships they embodied also shifted over time (Holmes, 2019). Stella, for example, explained that she had plans to declutter her flat in retirement:

There are some things I would like to keep and some things I don't particularly mind about. And perhaps one of the issues is to sort those out [in retirement].

What do I really need to keep and what do I not need? (Stella, London, 1)

One of the items she explained she would keep was a fruit knife, 'There's stuff I'd mourn if I didn't have it. But mostly they are small things like this fruit knife. It was a wedding present to my parents.' At some point, the fruit knife was damaged and her brother became part of the layers of memory it prompted as he repaired it for her: 'the original bone handle got burned or destroyed, so my brother when he was quite young, he put a new handle on it and bound it. And I still use it' (Stella, London, 1).

At the second interview, Stella held the knife in her hands and reiterated its story, in the context of having painted a picture for her brother to make up for an argument they had had:

And it [giving the picture] was a way of connecting, reconnecting with my brother because I had a very unfortunate phone call with him. I was, you know, a bit upset about that [argument] ... when he was a school boy he rescued a food knife that belonged to my mother that was damaged and he improvised a handle for it. (Stella, London, 2)

Sadly, by the third interview Stella's brother had died, and as a result of his loss, the possession of the fruit knife held even greater salience for her - the fruit knife was now symbolic of her brother and connected her to him, rather than to her parents: 'I think if there was a fire, I would take my brother's fruit knife' (Stella, London, 3).

The story of Stella's treasured fruit knife echoes Holmes' (2019) description of Diana's bread knife, also a wedding present passed on from grandmother to mother to daughter, in her work on the passing on of everyday objects, and with Dant's (2000) personal story of lifelong attachment to a knife he has taken with him on his own life journey. The connection between the knife stories of Stella, Diana and Dant is not only how people become attached to even seemingly mundane, easily replaceable things which happen to also be practical, but how those attachments can become more intense in light of shifts in relationships and loss, intensifying their significance for maintaining family connections. Such objects are therefore likely to remain within the household, and not disposed of (Miller, 2008; Holmes, 2019).

Yet this is not to say that all of the threads of affinity between people and their things were similarly strong or clearly defined, and participants were at times ambivalent about things that were important to them for their symbolic connection to family and for the comfort they bring, because they impinged on normative expectations that a home should be neat, and free of clutter, 'I like it to be kind 
of tidy and neat and fairly orderly and clean' (Veronica, London, 1). In her first interview Keira explained how her plans for retirement included sorting out her home, 'I'll probably tidy things up when I retire but not in the meantime' (Keira, Scotland, 1). Whilst she had not yet retired at her second interview, Keira had given further consideration to excess items she had, 'I want it out, it's too much, it's choc-a-block', but also how to make space for those things she particularly cherished but whose presence was impractical: 'the table in the kitchen was my granny's and it's far too big for the kitchen ... that'll go through [to a cleared out dining room]' (Keira, Scotland, 2).

One item Keira did not use, but which took up considerable space in her home, was a cocktail cabinet she had purchased: 'I'd seen it and I thought what am I wanting a cocktail cabinet for?' (Keira, Scotland, 2).

Yet, like Stella's knife, the cabinet held layers of meaning for Keira too which emerged within narratives of what was important to her in her home as she considered what to do with her possessions. Her appreciation for the skill of the maker of the cocktail cabinet blended with the memories of the day her son was killed:

I like stuff that's all been handmade, you know, that somebody's took time to carve and make. But I got that when my son died, but I didn't even know it was a cocktail cabinet, I thought it was just a cabinet. (Keira, Scotland, 1)

Whilst Keira had only just retired by the time of her third interview, her plans to keep busy whilst she still could and 'tidy up when I retire' were progressing: 'I just get on with it. You might not be here at the end of the month. If you're going to do it, do it' (Keira, Scotland, 3).

The preservation of possessions is also important for retaining a sense of self, especially in later life and when moving into residential care where they act as an 'archive' of memories and former identities from which to draw comfort (Belk, 1988; van Hoof et al., 2016). Retaining a sense of self can be especially important when relationships break down or new ones are formed. Just as personal biographies and individual identities are constructed through memories invoked by things, couples also shape a new couple identity through the negotiation of what things to keep or divest from previous relationships, and which items best signify and foreground the newly emerging one, allowing for a renewed 'critical alignment of persons with their possessions' (Miller, 2001: 13). Louise and her second husband were surrounded by things in their home that they had accrued during previous relationships, as well as things they had bought together:

I have got my mother's piano in the sitting room, and [husband] has got an old chest that belonged to his family. But we bought a new sofa because we needed a much bigger one. And the things around the house like paintings, the one in the hall was in my hall before. These paintings by Hogarth we bought together. So we have got a mixture of things on the walls that we have either chosen or we brought with us. Generally around the house we have got things that are a combination of our histories and our life together. This room is full of furniture we chose together and this I feel is the heart of the house for me because we chose it together. (Louise, London, 1) 
Louise's comment about one room being 'the heart of the house for me because we chose it together' highlights how things not only maintain connections to family and kin but are also significant in the making and remaking of couple identities. In the context of discussions about changes in retirement, Louise spoke of plans for her 'material convoy', which were modest and tentative:

I am trying to get rid of, not rid of, de-clutter a bit. I have got far too many clothes ... I am trying to find some winter clothes for people to wear. (Louise, London, 1)

Louise's use of the words 'trying' and 'a bit' suggests an ambivalence and reluctance to reduce her accumulated belongings, so the challenge for her therefore was how to manage the combined collections of her and her husband's items in the home, given she also finds it 'difficult to part with things of sentimental value' and can only pass things on to someone to whom she is emotionally connected: 'If something matters to me emotionally I want to give it to someone I like, I am a real old softie' (Louise, London, 1).

\section{'It's all got to go': clutter and the problem of stuff}

We have so far focused on those items in the 'material convoy' to which people have a strong affinity, but as Smith and Ekerdt (2011) have observed, even though the convoy fluctuates in size along the lifecourse, the eventual accrual of items, loved or otherwise, can become problematical at critical moments of transition in later life when the future prospect of downsizing the home and/or moving into residential care seems more imminent. Our own participants' responses suggested retirement is also a point at which individuals assess the suitability of their homes for the next stage of their lives. This included a reflection on the quantity of objects they had gathered around them. For several, this meant not only assessing the items they cherished and would keep, but also those which constituted unspecified 'clutter'. In contemplating retirement, Kenneth anticipated cutting down his already part-time hours before finally retiring, whilst also downsizing his home, 'Yes, it could all go on at the same time [retirement and moving] if you know what I mean' (Kenneth, London, 1). In the second interview, he partially explained his lack of progress in moving home and realising his post-retirement plans through reference to the accumulation of objects in his house:

It's a difficult thing to do [move home] ... it's the amount of clutter ... I just look around and think ah it is just full of stuff, it just goes on and on.

The ongoing presence of too much stuff presented as a barrier to his future plans, and prompted a critique of his own consumption habits: 'I'm a terrible hoarder' (Kenneth, London, 2).

We discussed earlier Margaret's reference to things in her home to which she was emotionally attached and would keep, but Margaret also demonstrated the complexity of material ownership in that some items within the 'material convoy' are precious, whilst others are merely 'clutter' and represent a challenge to the moral order of the home. Margaret explained that one of her goals, when she had more time after retiring, was to 'put the house in order', by getting rid of 
'piles of paper everywhere', which had led to her home going 'a little bit out of control'. Regaining control of her home and giving it a sense of order by removing unwanted matter was important to her normative expectations of how a home should be presented: 'Well yes you have your standards that you would like to keep the house [to] and I see some terrible places!' (Margaret, Scotland, 1). The use of language by participants like Margaret and Kenneth when referring to their household objects was suggestive of moral criticisms about the amount they had ('clutter', 'rubbish'), their own culpability in creating the 'problem' ('I'm a terrible hoarder', 'out of control') and how such clutter constitutes 'matter out of place' ('you have your standards') (Douglas, 1984).

Nevertheless, the objects which constituted 'clutter' were not always in plain sight, and participants spoke of discovering forgotten and unused items in the process of decluttering - like William who had emptied his loft, his van and his shed as part of his post-retirement efforts to bring order to his home, and in the process discovered collections of forgotten items: 'I think in the shed there was 30 pairs of shoes' (William, London, 3). Similarly Adele, whom we introduced earlier as anticipating retirement would give her the opportunity to clear out her clutter when she retired, rediscovered an extensive cookery book collection in her attic:

I can't believe the cookery books that I haven't looked at for years that were hidden away, and I'm really actually going to have to go through them and say ... I don't need all these, and get rid of some. (Adele, Scotland, 2)

Adele's project of decluttering continued across the transition to retirement, and she explained in her final interview how she had uncovered further items in her attic that had lain dormant and out of sight:

It's an ongoing project [in retirement]. The laugh was that I was going to go up in that attic ... and get looking to see what was up there. John [husband] went up and he came down with these two boxes. Opened them and there were boots that were probably about, well, as old as this house. So I said, 'I wonder if there's any more boots up there because that's terrible! (Adele, Scotland, 3)

Adele's self-rebuke ('that's terrible!') echoes Kenneth and Margaret's own selfcriticism for having such a large quantity of items, and for not remembering they were there. Moral judgements on lifelong acts of overconsumption, and criticisms of messiness, clutter and hoarding in the home and storage spaces were common, reflecting cultural discourses of the need for tidiness as a means of displaying a tasteful home (Dion et al., 2014), but also highlighting the tensions participants felt about what they should keep and what they could let go. Nevertheless, several participants acknowledged how decluttering contributed to a sense of wellbeing, albeit 'to an extent':

I find it therapeutic to do that [declutter] to a certain extent. (Stella, London, 3)

Every bag that I take to Oxfam makes me lighter and brighter. (Iris, Scotland, 2) 
William, Kenneth, Margaret and Adele's stories of clutter are indicative of how items are accumulated over time and along the lifecourse, and how they come to be stored out of sight and temporarily absent (Hetherington, 2004; Evans, 2012). Only when the transition to retirement afforded the opportunity to reconsider the spatial ordering of home were those items which crowded out the home, or were lying dormant in lofts, sheds, garages, drawers, cupboards and even spare vans, brought back into an unsettling presence through practices of sorting, handling and counting (Hetherington, 2004). Once back in plain sight, items were either subsumed into existing valued belongings or put on a trajectory for disposal (Hetherington, 2004; Evans, 2012).

\section{Moving things on}

Within participants' narratives of decluttering in retirement were stories of the final journey of their belongings and how they disposed of them. We suggest that the way they undertook disposal reveals a generationally distinctive attachment to thriftiness and frugality, and consider this in light of the literature on sustainable consumption and lifestyles.

Disposal, like consumption, constitutes a 'social activity' in that it requires attention to how, what and where objects are placed, by whom and to whom (Hetherington, 2004). Participants spoke of a wide variety of disposal practices ranging from giving to families, donating to charity, recycling and re-purposing, using digital forms of exchange (e.g. Freecycle, Gumtree and eBay) and the practice of 'leaving out' - or putting outside on the kerb for others to take. Only once all these methods had failed would objects became re-designated as waste and thrown away.

Finding the appropriate method of disposal required time, careful consideration and planning, as well as knowledge of local disposal organisations, and the ability to access them, thus comprising a 'labour of disposal' (Ekerdt and Baker, 2014). Christopher's description, for example, of how he got rid of items he no longer wanted after he had retired revealed his varied attempts at different modes of disposal, and how only items in bad repair were 'dumped':

Some of the furniture and things, we left quite a bit in the [church] and they said that if the next person can use it, that's fine. If not, then they'll give it to [local charity furniture shop]. They take stuff. One or two things went to them, one or two things went to other friends, clothes and stuff went to the charity shops. Some of it was just so bad it got dumped. (Christopher, Scotland, 2)

The re-purposing and recycling of items via different conduits of divestment other than the rubbish tip, and the placing of items back within spaces of use and re-use, such as charity shops or other digital exchange mechanisms, could therefore be argued to align with practices of more sustainable consumption and 'ridding' (Gregson, 2007). The household is increasingly targeted as the main focus for encouraging sustainable lifestyles, given its perceived role as a 'primary consumer' (Collins, 2015). Therefore, disposing of unwanted objects from the household by seemingly sustainable means would appear to tie into approaches which aim to shift households into more sustainable ways of consuming and disposing 
(Collins, 2015). Yet within the context of our own study there are two important observations to make about retirees' approaches to divestment which do not necessarily align directly with sustainable ways of living, but which nevertheless reveal how the current generation of retirees engage with consumption. Firstly, the attention to detail given to modes of disposal by participants was not explicitly as a result of environmental concerns, but rather was more aligned to how they valued thriftiness, and hated waste:

It's not about concern about the planet [taking unwanted items to recycling] because we don't have children so, you know, after us it doesn't really matter! It's just the thought of waste. We were poor as kids, relatively poor anyway, so nothing went to waste. (David, Scotland, 3)

Secondly, participants noted that their preferred mode of disposal was to pass on things to which they had an affinity, and those items they no longer needed, to younger family members. Their refusal to take them prompted comments on generational differences in attitudes to consumption. Younger generations were regarded as being reluctant to accept second-hand items, and to favour regularly updating what they owned (Leach et al., 2007):

We'll have lots of stuff we don't want - well not so much don't want, it won't fit, and the kids don't want it, it's hopeless, everything has to be new. (Kenneth, London, 1)

I wouldn't change things unless they kind of, I felt they needed it, I am not someone, my daughter's quite different, she likes to change things, you know it's a different generation. (Veronica, London, 1)

The sense of a generational divide in orientations to consumption was reinforced by participants aligning themselves to their parents' preferences for thriftiness and waste avoidance. Louise echoed David words about being brought up at a different time when thrift was valued and waste was disdained:

I was born during the war and brought up afterwards and I think that thriftiness never leaves you actually, I really think it's so ingrained, I can't bear to waste anything. (Louise, London, 3)

Yet in defining themselves as thrifty or frugal contra younger generations, participants failed to take account of how their homes had become sites of overconsumption in the first place, which led to them being compelled to dispose of some items as they transition through retirement.

\section{Discussion}

Our objective in this paper was to contribute to understandings of how those in the process of retiring orient themselves to their material possessions, the significance of this in terms of their wellbeing, and to reflect on how this can contribute to the currently limited work connecting later life and sustainable consumption. We 
demonstrated how the prospect of retirement prompted considerations as well as concerns for a post-work future, and led to a reassessment of the suitability of the material possessions within the home for later life. We found that even seemingly mundane things in everyday use prompted memories, and stories of kinship connections, and that these threads of connectivity were significant in the making and remaking of identities. As such, possessions were important to participants' sense of wellbeing in that they provided context, continuity and attachment to lost, current and future generations (Holmes, 2019). Contrastingly, our research also showed that the prospect of retirement highlighted the 'spectre' of the 'material convoy' of possessions that had the potential to burden participants with the labour of their management and disposal (Ekerdt et al., 2004). We demonstrated how the end-point of consumption was not straightforward in that divesting was carefully managed so that the emphasis was placed on putting items back into use, and as such would ostensibly suggest an alignment with sustainable lifestyles. However, the way possessions were disposed of was more as a result of a generational habitus defined by thrift and frugality, in contrast to perceptions of younger generations' habitus of a rejection of such values.

The connections between people and their things were ambiguous and did not comprise a simple binary of affinity or burden, and decisions on what to keep or divest were further complicated by the 'messiness' of lifecourse transitions. We turn now to discuss this in more detail.

\section{Degrees of affinity}

Whilst most participants had a sense of which things they would absolutely retain, and what stuff they would definitely dispose of, the remainder of the 'material convoy' elicited varying degrees of connectivity which made decisions on what to keep, what to pass on or what to dispose of more complex (Holmes, 2019). Not all cherished things were to be kept, and not all items that were deemed clutter were considered for disposal. Rather, participants like Margaret considered the consolidation of their belongings in light of other factors, including how much space they envisaged having in retirement, the role of their belongings in the making and remaking of home, and whether or not they impinged on the norms of how homes should be presented - for themselves and to others (Oullette, 2019). In the case of couples, the question of whose cherished things could be moved on and whose would be kept also depended on negotiations around which partner's items had precedence when space was limited.

\section{Transitions are messy}

Participants anticipated that retirement would afford them the opportunity to assess the suitability of their surroundings and their possessions for the next phase of their lives. This would also align with the 'moment of change' hypothesis whereby transitions are viewed as points of contemplation, when people may be more open to shift existing consumption patterns in a more sustainable direction (Thompson et al., 2011; Burningham and Venn, 2020). However, whilst retirement was a time of significant change in the participants' everyday lives and lifestyles, we 
would argue that the idea of retirement as a single 'moment of change' is too simplistic and does not capture the complexity of their lives as they transitioned into retirement (Burningham and Venn, 2020). One of the benefits of longitudinal research is that it offers the opportunity to follow individuals on their lifecourse journey and discover whether aspirations were fulfilled or not, what had changed and what remained the same (Neale and Flowerdew, 2003). Being able to accompany participants on their pathway through retirement enabled us to observe the progress or otherwise of their plans towards putting their homes in order, and to observe two confounding factors. Firstly, whilst some participants, like William and Keira, made significant progress in decluttering their homes, the reality for those like Kenneth was that the pathway to retirement was not straightforward, and the interconnectedness of family lives meant that plans to divest were permanently halted, partially stalled or never started at all. Over the course of the three interviews, participants experienced multiple interruptions to their plans, including personal or family health issues, unexpected financial changes, and the breakdown of family or community relationships. Furthermore, for some, the reality of such 'linked lives' led to an increase in items in the home when adult family members moved back home along with their own belongings (Burningham and Venn, 2020).

Secondly, whilst retirement is regarded as a lifecourse transition, marking the end of employment and the beginning of a new phase of life, it was also regarded by participants as a temporary transition, pointing to the next stage of the lifecourse of moving into a smaller home, a managed home, into care and/or into a final transition of death. In addition, the prospect of declining health, increasing frailty and possible reduced financial circumstances was unsettling. The significance of this is that for many participants decisions on what to dispose of or what to retain were more challenging in light of unknown and unknowable future transitions in mind.

The transition to retirement highlighted to participants the consequences of lifelong acts of consumption, and the need to make plans for how to manage the 'material convoy'. Given that it is known the acquisition of material goods and the labour that is required in their disposal negatively impact wellbeing, and that overconsumption has negative consequences for the environment, there are arguments for making systemic changes which discourage the accumulation of 'stuff at much earlier points along the lifecourse (Ekerdt et al., 2004; Dittmar et al., 2014; Jackson, 2016).

\section{Conclusions}

In this paper, we have drawn on the different fields of gerontology, consumption and environmental sustainability, and in so doing have sought to move critical work on the consumption and divestment practices of the current generation of retirees into the arenas of sustainable lifestyles and consumption. Within this arena, existing work has tentatively explored retirement as a 'moment of change' for encouraging sustainable lifestyles, but has mostly focused on the oldest old and their vulnerability to climate change and environmental risks (Filiberto et al., 2008). Including a recognition of the diversity of later-life experiences, lifestyles, and consumption or divestment practices within sustainability research is timely, given those currently in the process of retiring, or approaching it, are greater in number, healthier and, for the most part, better off financially than preceding 
generations (Biggs et al., 2007; Boerenfijn et al., 2018). If, as Biggs et al. (2007: 34) suggest, the retiring 'baby boomer' generation' use consumption as part of their wider strategies in coping with the challenge of growing older then having a clearer understanding of the role of consumption in their generational habitus should not be left out of work on sustainable consumption.

Exploring the ridding practices of those making the transition to retirement would also reveal more about the 'material convoy' of the baby-boomer generation and to what extent they have 'overprovisioned their homes' (Ekerdt and Baker, 2014: 448). This will be increasingly important as they progress through retirement and into later life, along with the objects they have retained.

Finally, we suggest that gerontologists may wish to consider critically engaging and connecting with environmental sustainability research. For example, focusing on the ridding of objects at the later transitions of the fourth age is problematic in that unwanted items remain a spectre to be tackled most commonly by family members or even one of the increasing number of service industries which cater for house clearances (Smith and Ekerdt, 2011). If the burden or labour of divestment shifts to younger family members, or external services who are less invested in thrifty ways of disposal, there is more potential for the flow of materials to end at the rubbish tip, rather than finding its way back into use and re-use (Ekerdt et al., 2004). Shifting such research to lie within a sustainability framework offers the possibility of reshaping current discourses that present older people as a burden on resources and/or as being solely responsible for climate change (Karpf, 2020).

Acknowledgements. The authors gratefully acknowledge the Department for Environment and Rural Affairs (Defra), the Economics and Social Research Council and the Scottish Government for funding of the project; the participants for taking part in the research; and the support of colleagues within the Centre for the Understanding of Sustainable Prosperity (CUSP).

Financial support. This work was initially supported by funding from the Department for Environment and Rural Affairs (Defra); the Economics and Social Research Council; and the Scottish Government and continued under CUSP, Centre for the Understanding of Sustainable Prosperity, funded by the Economics and Social Research Council - grant number ES/M008320/1.

Ethical standards. Ethical approval was granted by the University of Surrey Ethics Committee (EC/2010/ 132/FAHS).

\section{References}

Atchley RC (1975) The Sociology of Retirement. Cambridge, MA: Schenkman.

Barnes H and Parry J (2004) Renegotiating identity and relationships: men and women's adjustments to retirement. Ageing \& Society 24, 213-233.

Bauer M, Wilkie J, Kim J and Bodenhausen G (2012) Cuing consumerism: situational materialism undermines personal and social well-being. Journal of Psychological Science 23, 517-523.

Belk RW (1988) Possessions and the extended self. Journal of Consumer Research 15, 139-168.

Biggs S, Phillipson R, Leach R and Money A (2007) Baby boomers and adult ageing: issues for social and public policy. Quality in Ageing 8, 32-40.

Boerenfijn P, Kazak JK, Schellen L and van Hoof J (2018) A multi-case study of innovations in energy performance of social housing for older adults in the Netherlands. Energy and Buildings 158, 1762-1769.

Bourdieu P (1984) Distinction: A Social Critique of the Judgement of Taste. London: Routledge.

Brown HS and Vergragt P (2015) From consumerism to wellbeing: toward a cultural transition? Journal of Cleaner Production 132, 308-317. 
Burningham K and Venn S (2020) Are lifecourse transitions opportunities for moving to more sustainable consumption? Journal of Consumer Culture 20, 102-121.

Coates S, Tanna P and Scott-Allen E (2019) Overview of the UK Population August 2019. Office for National Statistics. Available at https://www.ons.gov.uk/peoplepopulationandcommunity/populationandmigration/populationestimates/articles/overviewoftheukpopulation/august 2019.

Collins R (2015) Keeping it in the family: refocusing household sustainability. Geoforum 60, 22-32.

Csikszentmihalyi M and Rochberg-Halton E (1981) The Meaning of Things: Domestic Symbols and the Self. New York, NY: Cambridge University Press.

Dant T (2000) Consumption caught in the 'cash nexus'. Sociology 34, 655-670.

Dion D, Sabri O and Guillard V (2014) Home sweet messy home: managing symbolic pollution. Journal of Consumer Research 41, 565-589.

Dittmar H (1991) Meanings of material possessions as reflections of identity: gender and social-material position in society. Journal of Social Behavior and Personality 6, 165-186.

Dittmar H, Bond R, Hurst $\mathbf{M}$ and Kasser T (2014) The relationship between materialism and personal well-being: a meta-analysis. Journal of Personality and Social Psychology 107, 879-924.

Douglas M (1984) Purity and Danger. London: Routledge.

Easterlin R (1974) Does economic growth improve the human lot? Some empirical evidence. In David PA and Reder MW (eds), Nations and Households in Economic Growth: Essays in Honor of Moses Abramovitz. New York and London: Academic Press, pp. 89-125.

Ekerdt DJ (1986) The busy ethic: moral continuity between work and retirement. The Gerontologist 26, 239-244.

Ekerdt DJ and Baker LA (2014) The material convoy after 50. Journals of Gerontology: Psychological Sciences and Social Sciences 69B, 442-450.

Ekerdt DJ, Sergeant JF, Dingel M and Bowen ME (2004) Household disbandment in later life. Journals of Gerontology: Psychological Sciences and Social Sciences 59B, S265-S273.

Evans D (2012) Binning, gifting and recovery: the conduits of disposal in household food consumption. Environment and Planning D: Society and Space 30, 1123-1137.

Evans E (2015) Shopping and Successful Ageing: A New Approach to Promoting Health and Wellbeing in Later Life (PhD thesis). University of Liverpool, Liverpool, UK.

Evans C (2018) Analysing Semi-structured Interviews Using Thematic Analysis: Exploring Voluntary Civic Participation Among Adults (Sage Research Methods Datasets). London: Sage.

Filiberto D, Wethington E, Pillemer K, Wells N, Wysocki M and Parise J (2008) Older people and climate change: vulnerability and health. Generations 33, 19-25.

Fox E, Hitchings R, Day R and Venn S (2017) Demanding distances in later life leisure travel. Geoforum 82, $102-111$.

Giddens A (1991) Modernity and Self Identity: Self and Society in the Late Modern Age. Cambridge: Blackwell Publishing.

Gilleard C and Higgs P (2009) The third age: field, habitus or identity? In Rees-Jones I, Higgs P and Ekerdt DJ (eds), Consumption and Generational Change: The Rise of Consumer Lifestyles. New Brunswick, NJ: Transaction Publishers, pp. 23-36.

Gilleard C and Higgs P (2013) The fourth age and the concept of a 'social imaginary': a theoretical excursus. Journal of Aging Studies 27, 368-376.

Ginn J (2003) Gender Pensions and the Life Course: How Pensions Need to Adapt to Changing Family Forms. Bristol, UK: Policy Press.

Goodwin J and O'Connor H (2014) Notions of fantasy and reality in the adjustment to retirement. Ageing \& Society 34, 569-589.

Gregson N (2007) Living with Things: Ridding, Accommodation, Dwelling. Oxford: Sean Kingston Publishing.

Gregson N, Metcalfe A and Crewe L (2007) Moving things along: the conduits and practices of divestment in consumption. Transactions of the Institute of British Geography 32, 187-200.

Grenier A (2012) Transitions and the Lifecourse, Challenging the Construction of 'Growing Old'. Bristol, UK: Policy Press.

Habermas T and Praha C (2002) Souvenirs and other personal objects: reminding of past events and significant others in the transition to university. In Webster JD and Haight BK (eds), Critical Advances in Reminiscence Work. New York, NY: Springer, pp. 123-138. 
Hand M, Shove E and Southerton D (2005) Explaining showering: a discussion of the material, conventional, and temporal dimensions of practice. Sociological Research Online 10, 2, 101-113.

Heaven B, O'Brien N, Evans EH, White M, Meyer TD, Mathers JC and Moffatt S (2015) Mobilizing resources for well-being: implications for developing interventions in the retirement transition. The Gerontologist 56, 615-629.

Hetherington K (2004) Secondhandness: consumption, disposal and absent presence. Environment and Planning D: Society and Space 22, 157-173.

Hitchings R, Venn S and Day R (2018) Assumptions about later life travel and their implications: pushing people around? Ageing \& Society 38, 1-18.

Holmes H (2019) Material affinities: 'doing' family through the practices of passing on. 53, 174-191.

Horne R, Malle C and Lane R (2011) Remaking home: the reuse of goods and materials in Australian households. In Gorman-Murray A (ed.), Material Geographies of Household Sustainability. London, UK: Routledge, pp. 89-115.

Ingold T (2010) Bringing things to life: creative entanglements in a world of materials. World 44, 1-25.

International Longevity Centre UK (2019) Maximising the Longevity Dividend. Available at https://ilcuk. org.uk/wp-content/uploads/2019/12/Maximising-the-longevity-dividend.pdf.

Isham A, Gatersleben B and Jackson T (2019) Flow activities as a route to living well with less. Environment and Behaviour 51, 431-461.

Jackson T (2005a) Live better by consuming less: is there a double dividend in sustainable consumption. Journal of Industrial Ecology 9, 19-36.

Jackson T (2005b) Motivating Sustainable Consumption: A Review of Evidence on Consumer Behaviour and Behavioural Change. Sustainable Development Research Network, 5. Available online at https://www. researchgate.net/publication/275638627_Motivating_Sustainable_Consumption_A_Review_of_Evidence_ on_Consumer_Behaviour_and_Behavioural_Change (Accessed on 3 August 2020).

Jackson T (2016) Prosperity Without Growth, 2nd Edn. Abingdon, UK: Routledge.

Karpf A (2020) Don't let prejudice against older people contaminate the climate movement. The Guardian, January 18. Available at https://www.theguardian.com/commentisfree/2020/jan/18/ageism-climate-movement-generation-stereotypes.

Kondo M (2011) The Life-changing Magic of Tidying Up: The Japanese Art of Decluttering and Organizing. London: Vermilion.

Kroger J and Adair V (2008) Symbolic meanings of valued personal objects in identity transitions of late adulthood. Identity: An International Journal of Theory and Research 8, 5-24.

Ladik D, Carrillat F and Tadajewski M (2015) Belk's (1988) 'Possessions and the extended self revisited. Journal of Historical Research in Marketing 7, 184-207.

Leach R, Biggs S, Phillipson C and Money A (2007) Boomers and Beyond: Intergenerational Consumption and the Mature Imagination (ESRC End of Award Report RES-154-25-0003). Available at http://www. consume.bbk.ac.uk/research/biggs.html (Accessed 20 March 2020).

Lee WKM and Law KWK (2004) Retirement planning and retirement satisfaction: the need for a national retirement program and policy in Hong Kong. Journal of Applied Gerontology 23, 212-233.

Löfgren O (2017) Mess: on domestic overflows. Consumption Markets \& Culture 20, 1-6.

Magnusson M (2017) The Gentle Art of Swedish Death Cleaning: How to Free Yourself and Your Family from a Lifetime of Clutter. Edinburgh: Canongate Books.

Miller D (2001) Home Possessions: Material Culture Behind Closed Doors. Oxford: Berg.

Miller D (2008) The Comfort of Things. Cambridge: Polity Press.

Miller D (2010) Stuff. Cambridge: Polity Press.

Miller D (2012) Consumption and Its Consequences. Cambridge: Polity Press.

Moffatt S and Heaven B (2017) 'Planning for uncertainty': narratives on retirement transition experiences. Ageing \& Society 37, 879-898.

Neale B and Flowerdew J (2003) Time, texture and childhood: the contours of longitudinal qualitative research. International Journal of Social Research Methodology 6, 189-199.

Norris JI and Larsen JT (2010) Wanting more than you have and its consequences for well-being. Journal of Happiness Studies 12, 877-885.

Oullette L (2019) Spark joy? Compulsory happiness and the feminist politics of decluttering. Culture Unbound 11, 534-555.

Patton MQ (2002) Qualitative Research and Evaluation Methods, 3rd Edn. Thousand Oaks, CA: Sage. 
Price LL, Arnould EJ and Curasi CF (2000) Older consumers' disposition of special possessions. Journal of Consumer Research 27, 179-201.

Saldaña J (2003) Longitudinal Qualitative Research: Analyzing Change Through Time. Walnut Creek, CA: AltaMira Press.

Schor J (1997) The Overspent American, Why We Want What We Don't Need. New York, NY: HarperCollins.

Schulze G (1997) From situations to subjects: moral discourse in transition. In P Sulkunen, J Holmwood, H Radner and G Schulze (eds), Constructing the New Consumer Society. London: Macmillan, pp. 38-57.

Shankar A, Elliott R and Fitchett JA (2009) Identity, consumption and narratives of socialization. Journal of Marketing Theory 9, 75-94.

Shirani F, Groves C, Parkhill KA, Butler C, Henwood K and Pidgeon N (2017) Critical moments? Life transitions and energy biographies. Geoforum 86, 86-92.

Smith GV and Ekerdt DJ (2011) Confronting the material convoy in later life. Sociological Inquiry 81, 377-391.

Stevens D, Camic PM and Solway R (2019) Maintaining the self: meanings of material objects after a residential transition later in life. Educational Gerontology 43, 214-226.

Thompson S, Michaelson J, Abdallah S, Johnson V, Morris D, Riley K and Simms A (2011) 'Moments of Change' as Opportunities for Influencing Behaviour: A Report to the Department for Environment, Food and Rural Affairs. London: nef (the new economics foundation) and Department for Environment, Food and Rural Affairs.

Trentmann F (2018) Empire of Things. London: Penguin Books.

van Hoof J, Verbeek H, Janssen BM, Eijkelenboom A, Molony SL, Felix E, Nieboer KA, Zwerts-Verhelst ELM, Sijstermans JJWM and Wouters EJM (2016) A three perspective study of the sense of home of nursing home residents: the views of residents, care professionals and relatives. BMC Geriatrics 16, 169.

Van Oyen A (2020) Hoarding in Times of Corona: thoughts on storage, stuff and the future. Cambridge Blog, Cambridge. Available online at http://www.cambridgeblog.org/2020/05/hoarding-in-times-of-coronathoughts-on-storage-stuff-and-the-future/ (Accessed 10 August 2020).

van Solinge $\mathbf{H}$ and Henkens $\mathbf{K}$ (2008) Adjustment to and satisfaction with retirement: two of a kind? Psychology and Aging 23, 422-434.

Venn S, Burningham K, Christie I and Jackson T (2017) Consumption junkies or sustainable consumers: considering the grocery shopping practices of those transitioning to retirement. Ageing \& Society 37, $14-38$.

Cite this article: Venn S, Burningham K (2022). Managing the retention or divestment of material possessions in the transition to retirement: implications for sustainable consumption and for later-life wellbeing. Ageing \& Society 42, 2082-2102. https://doi.org/10.1017/S0144686X20001993 